\title{
Efficacy of electrical stimulation on epidural anesthesia for cesarean section: a randomized controlled trial
}

\author{
Young Sung Kim, Hyo Sung Kim, Hyerim Jeong, Chung Hun Lee, Mi Kyoung Lee and Sang Sik Choi* (D)
}

\begin{abstract}
Background: Loss of resistance (LOR) technique is a widely used method to identify the epidural space. However, cases of inadequate epidural anesthesia in cesarean section were frequently reported. Also, the success rate of epidural anesthesia with LOR technique varied depending on the proficiency of the practitioner. The purpose of this study was to assess the efficacy and safety of electrical stimulation to identify epidural spaces in cesarean section for novices or clinicians with recent gap in experience.
\end{abstract}

Methods: Pregnant women scheduled for elective cesarean section were randomly allocated to two groups. Groups were classified based on the methods used for identifying the epidural space: the LOR group (group L) and the LOR with epidural electrical stimulation group (group E). Clinicians with less than 10 epidural cesarean section experiences in the recent year performed epidural anesthesia for cesarean section. In the group E, a RegionalStim ${ }^{\circledast}$ conductive catheter was inserted through the Tuohy needle, and the guidewire passing through the catheter was connected to a peripheral nerve stimulator. The intensity of the stimulation was gradually increased from $0.25 \mathrm{~mA}$ to $1.5 \mathrm{~mA}$ until paresthesia was elicited and radiated. We assessed the success of epidural anesthesia (complete success, partial success or failure). Other clinical parameters including maternal satisfaction, time required for epidural anesthesia, neonatal Apgar scores, pain scores and adverse events were compared between the two groups.

Results: Except for 6 patients who withdrew consent, 54 patients were enrolled in this study (28 for the group L and 26 for the group E). The demographic data showed no difference between the two groups. There was no adverse event resulted from electrical stimulation. The group E showed higher rate of complete success, sensitivity in finding epidural space and maternal satisfaction compared to the group $L(21 / 26 \mathrm{vs} .15 / 28, p=0.034,0.96 \mathrm{vs}$. $0.68, p=0.012$ and 4.04 vs. 3.39, $p=0.02$, respectively). The other clinical parameters showed no differences between the two groups.

Conclusion: In addition to the conventional LOR technique, identifying epidural spaces using electrical stimulation led to better outcomes without additional risks for novices as well as clinicians with recent gap in experience.

Trial registration: This study was retrospectively registered in the ClinicalTrials.gov Registry (NCT03443466) on February 23, 2018.

Keywords: Cesarean section, Electrical stimulation, Epidural anesthesia

\footnotetext{
* Correspondence: clonidine@empal.com

Department of Anesthesiology and Pain Medicine, Korea University Guro

Hospital, 148 Gurodong-ro, Guro-gu, Seoul 08308, South Korea
}

(c) The Author(s). 2020 Open Access This article is licensed under a Creative Commons Attribution 4.0 International License, which permits use, sharing, adaptation, distribution and reproduction in any medium or format, as long as you give appropriate credit to the original author(s) and the source, provide a link to the Creative Commons licence, and indicate if changes were made. The images or other third party material in this article are included in the article's Creative Commons licence, unless indicated otherwise in a credit line to the material. If material is not included in the article's Creative Commons licence and your intended use is not permitted by statutory regulation or exceeds the permitted use, you will need to obtain permission directly from the copyright holder. To view a copy of this licence, visit http://creativecommons.org/licenses/by/4.0/ The Creative Commons Public Domain Dedication waiver (http://creativecommons.org/publicdomain/zero/1.0/) applies to the data made available in this article, unless otherwise stated in a credit line to the data. 


\section{Background}

Epidural analgesia and anesthesia are widely used in the obstetrical area. Especially in labor, the usefulness of epidural analgesia is remarkable [1]. Epidural analgesia showed high maternal satisfaction as mothers can walk and move freely with effective labor pain relief [2]. In the cases for cesarean section, epidural anesthesia also demonstrated many advantages than other anesthetic techniques especially for the parturient with congenital heart disease [3]. However, spinal anesthesia appeared to be preferred over epidural anesthesia in the cesarean section [4]. Compared to the epidural analgesia, epidural anesthesia for cesarean section requires more intense anesthesia with wider dermatome levels. When converting epidural labor analgesia into surgical anesthesia for cesarean section, the rate of conversion failure has been reported up to almost 20\% [5]. Interestingly, the rate of failed epidural anesthesia conversion was 4.5 times higher for non-specialist anesthesiologists than among obstetric anesthesiologists [6].

In clinical practices, the success rate of epidural anesthesia varied depending on the proficiency of the practitioner [7]. Moreover, from a teaching standpoint, it was difficult to determine immediately whether a resident or novice practitioner had properly performed epidural anesthesia. In the case of spinal anesthesia, the success of the procedure can be predicted mostly by free CSF flow. On the other hand, loss of resistance (LOR) technique, which is widely used for confirmation in epidural anesthesia, is relatively subjective to interpret. Kopacz. et al. [8] reported 60 attempts at epidural anesthesia may be necessary to achieve a $90 \%$ success rate. We expected that untrained practitioner would have problems, especially in finding epidural spaces. In addition, proper placement of the epidural catheter may be difficult, particularly when performed by a novice provider.

We have previously shown the utility of electrical stimulation-guided epidural analgesia for vaginal delivery [9]. We thought that electrical stimulation would be also applied to the epidural confirmation for cesarean section. In the present study, we demonstrated the efficacy and the safety of electrical stimulation when confirming epidural spaces in cesarean section. We hypothesized that electrical stimulation-guided epidural anesthesia may help to find a correct epidural space and may result in a higher success rate for novices or clinicians with recent gap in experience.

\section{Methods}

\section{Study population}

This study was a single-center prospective randomized controlled trial conducted at Korea University Guro Hospital from 2018 to 2019. After obtaining approval from the Korea University Guro Hospital Institutional Review Board (IRB number 2015GR0703), written informed consent was obtained from all subjects participating in the trial. The trial was retrospectively registered at the ClinicalTrials.gov (trial identifier: NCT03443466). The current study was presented in accordance with the Consolidated Standards of Reporting Trials (CONSORT) guidelines. All patients were recruited from the Department of Obstetrics and Gynecology, Korea University Guro Hospital, by the research staff and were enrolled in the study at the hospital before surgery. Written informed consent was obtained from all participants after providing an explanation of the trial.

Patients aged 20 to 42 years, at 36 to 41 weeks' gestation, of American Society of Anesthesiologists (ASA) physical status I to II, and scheduled for cesarean section under epidural anesthesia were included in the study. Patients with severe cognitive impairment, skin infection on the back, history of lidocaine allergy and lumbar surgery, lumbar deformity, and hemostatic disorder were excluded from the study. Those undergoing anticoagulant therapy, having cardiopulmonary compromised status and expecting twin delivery, as well as those who refused to participate were also excluded. Demographic data including age, weight, height, and ASA class were collected from all the patients (Table 1). Patients were randomly allocated to the LOR group (group L) or the LOR + electrical stimulation group (group E), and they were unaware of the group assignment before the surgery. A single independent investigator was responsible for the random allocation sequence generation and the group assignment of patients. Randomization was achieved into 2 blocks using a web-based computergenerated list (www.randomization.com). The subject numbers were kept in opaque, sealed envelopes that were opened in the operating room by an independent anesthesiologist not involved in the study. Both the

Table 1 Demographic data

\begin{tabular}{lll}
\hline & $\begin{array}{l}\text { Group L } \\
(\boldsymbol{n}=28)\end{array}$ & $\begin{array}{l}\text { Group E } \\
(\boldsymbol{n}=26)\end{array}$ \\
\hline Age (years) & $35.93 \pm 2.54$ & $35.15 \pm 4.76$ \\
Weight (kg) & $66.56 \pm 8.74$ & $71.18 \pm 6.69$ \\
Height (cm) & $159.48 \pm 6.10$ & $160.65 \pm 7.67$ \\
Body mass index (kg/m²) & $26.17 \pm 3.09$ & $27.67 \pm 4.00$ \\
ASA class (I / II) & $7 / 21(25 / 75)$ & $6 / 20$ (23 / 77) \\
Status of practitioners & $4 / 8 / 2 / 6 / 8$ & $4 / 8 / 2 / 7 / 5$ \\
(R1 / R2 / R3 / R4 / Specialist) & & \\
\hline
\end{tabular}

Values are either the mean \pm SD or the number of patients (\%). Group L used a loss of resistance technique in the epidural cesarean section while group $E$ used electrical epidural stimulation combined with a loss of resistance technique. There was no significant difference between the two groups. ASA class refer to American Society of Anesthesiologists physical status. R1, R2, R3 and R4 refer to first-, second-, third- and fourth-year residents 
patients and principal investigator were blinded to group allocation.

\section{Anesthetic protocol}

Routine monitoring devices including non-invasive blood pressure measurement, electrocardiogram and pulse oximetry were applied to each patient. We also monitored temperature and urine output during the perioperative period. The baseline values for each measurement were recorded before anesthesia induction. Epidural procedures were performed by anesthesiologists who were novice or with a recent gap in experience (less than 10 experiences for epidural cesarean section in the recent year). A resident who meets the conditions first attempted the procedure. If the residents did not find an epidural space after two attempts, another anesthesiologist who was a specialist performed the procedure. We considered that the practitioners have used one chance to attempt in any of the following circumstances: a) he or she gave up finding an epidural space and changed the injection site, b) the epidural catheter could not be inserted, and c) the leakage of blood or CSF was suspected. They did not know the group assignment for each patient until the test dose administration. The level of their anesthetic experience and status, ranging from first year to fourth year (resident or specialist), were recorded for each case.

After oxygen mask application with $5 \mathrm{~L} / \mathrm{min}$ of oxygen, for the epidural catheter placement, patients were placed in the left lateral decubitus position. Once a sterile drape was performed, a local infiltration with $1 \%$ lidocaine was done at the L2/3 intervertebral level. A midline approach was used with a 17-guage Tuohy needle. Epidural space was then identified using LOR with air. After ensuring no cerebrospinal fluid or blood, $3 \mathrm{ml}$ of $1 \%$ lidocaine (30 $\mathrm{mg}$ ) was administrated as a test dose. In the group $\mathrm{E}$, an epidural catheter (20-gauge, open tip catheter, $800 \mathrm{~mm}$ of length, Regional Stim ${ }^{\circ}$ Sewoon Medical Co., Ltd., Korea) with a conductive guidewire (Nitinol, $1100 \mathrm{~mm}$ of length; $800 \mathrm{~mm}$ inside the catheter and $300 \mathrm{~mm}$ exposed for connection to the electric nerve stimulator) was inserted $3 \mathrm{~cm}$ cephalad beyond the tip of the Tuohy needle right after a test dose administration. The cathode of the electric nerve stimulator (Stimuplex ${ }^{\circ}$ HNS 12, B. Braun Melsungen, Germany) was connected to the exposed guidewire, and the anode was attached to an electrode on the patient's calf. For stimulation, the electric current was gradually increased from $0 \mathrm{~mA}$ to $2 \mathrm{~mA}$, with a frequency of $1 \mathrm{~Hz}$ and pulse-width of $300 \mathrm{~ms}$. A minimum required current to elicit paresthesia of a dermatome or motor response of a muscle group including the hip adductors, iliopsoas, gluteus, and hamstrings was recorded for each patient. Usually the current was checked within $3 \mathrm{~min}$, so once epidural space was confirmed by electrical stimulation, the guidewire was removed, and the patient was observed for the remaining time until $3 \mathrm{~min}$ past the test dose administration. If there was no adverse sign and intrathecal injection was not suspected, $18 \mathrm{ml}$ of $2 \%$ lidocaine was injected via the epidural catheter as a main dose. In the group L, the same process followed the test dose administration except the electrical stimulation. The same guidewire embedded epidural catheter was inserted, and the guidewire was immediately removed. $3 \mathrm{~min}$ after the test dose administered, $18 \mathrm{ml}$ of $2 \%$ lidocaine was injected via the epidural catheter as a main dose. The patient was thereafter placed on the supine position.

The cold sensory test was performed with an alcohol swab. The additional epidural bolus, $5 \mathrm{ml}$ of $0.75 \%$ ropivacaine, was injected through the epidural catheter when the cold sensory blockade did not reach a T7 level in 10 min after the main dose administration or when the patient complained of pain during surgery. After the baby was delivered, 2 ample (20 IU) of oxytocin was mixed to the main fluid for the mother, and the Apgar scores of the baby were assessed at $1 \mathrm{~min}$ and $5 \mathrm{~min}$. When hypotension occurred during the perioperative period, ephedrine $4 \mathrm{mg}$ or phenylephrine $50 \mathrm{mcg}$ was administered intravenously to keep the systolic blood pressure at -20 to $20 \%$ of the baseline value. Any complications were recorded during the perioperative period.

\section{Study endpoints}

The primary outcome was a success rate of epidural anesthesia. We assessed each case as "complete success", "partial success" or "failure". If there were no signs for motor and sensory blockade in $10 \mathrm{~min}$ after epidural main dose administration, we regarded it as a "failure" and the anesthesia was converted to general anesthesia. If epidural anesthesia did not reach appropriate range and intensity and if the additional ropivacaine bolus was required, it was regarded as a "partial success". If the anesthesia was maintained enough to proceed with surgery, it was considered as a "complete success". The rate of complete success in epidural anesthesia was calculated as "complete success / complete success + partial success + failure". And the sensitivity in finding the epidural space was calculated as "complete success + partial success / complete success + partial success + failure" in each group. Meanwhile, calculation of the specificity was not available due to methodological limitation.

The secondary outcomes include Apgar scores, presence or absence of hypotension and ephedrine or phenylephrine use during perioperative periods, anesthetic times, fluids, transfusion, urine output, blood loss, pain score $1 \mathrm{~h}$ after arrival at PACU, maternal satisfaction, nausea/vomiting and other complications. Oneand 5-min Apgar scores were compared to assess the 
effects of epidural electrical stimulation on the neonate. Anesthesia time was recorded in detail as described below: Time interval between operation room admission and the start of the operation, time A (interval between drape and the test dose administration), time B (time it took to confirm epidural space, place epidural catheter and administer main dose), operation time, time interval between the end of the operation and discharge to the post-anesthesia care unit (PACU). A blinded independent anesthesiologist assessed postoperative pain and other complications in the PACU. Pain was assessed by a visual analogue scale (VAS) score on an 11-point scale, where 0 indicates no pain and 10 refers to unbearable pain. Maternal satisfaction was evaluated by a postpartum interview. It was rated on a scale ranging from 1 to 5 , where 1 represents very unsatisfied and 5 represents very satisfied.

\section{Sample size and statistical analysis}

A power analysis suggested that a minimum sample size of 26 patients for each group would be required with a significance level of $5 \%$ to achieve a power of $90 \%$. It was calculated from our preliminary data: complete success rates of 0.9 for electrical stimulation group and 0.5 for conventional group. To allow for an exclusion rate, the study population was prospectively set at 60 patients.

Statistical analyses were performed with SPSS 22 (IBM, Armonk, NY, USA, Statistical Package for the Social Science 22). The outcomes were assessed based on the intention-to-treat analysis. Data expressed as mean \pm standard deviation were tested for normality using the Kolmogorov-Smirnov test and were compared using independent t-tests or Mann-Whitney $U$ tests depending upon the results of the Kolmogorov-Smirnov analysis. Finally, data expressed as the number of patients were compared using chi-square analysis or Fisher's exact test as appropriates. A $p$-value of $<0.05$ was considered significant.

\section{Results}

The CONSORT flow diagram is presented in Fig. 1. Total 54 patients were enrolled in this study (28 patients in the group $\mathrm{L}$ and 26 patients in the group E) except 6 patients who withdrew consent due to anxiety and family opposition with no particular event prior to the cesarean section.

Demographic data including age, weight, height, body mass index, and ASA class showed no significant differences between the two groups (Table 1). The minimum electric current used to evoke paresthesia or muscle contraction in the group $\mathrm{E}$ was $1.06 \pm 0.36 \mathrm{~mA}$. Unilateral response was observed in 16 cases (62\%) while bilateral response was observed in 10 cases (38\%) (Table 2). Unilateral response did not correlate with "partial success" or "failure". Patients with unilateral and bilateral responses exhibited comparable patterns, such that those with unilateral responses reported 13 "complete success" and 3 "partial success" and that those with bilateral responses reported 8 "complete success", 1 "partial success" and 1 "failure". (Table 2).

The rate of "complete success" was significantly higher in the group E $(53.6 \%$ for group L versus $80.8 \%$ for group E) (Table 3 ). In addition, the sensitivity of LOR + electrical stimulation in finding epidural space in the group E was 0.961 (25/26), whereas the sensitivity of LOR in the group L was 0.679 (19/28) (Table 3). Especially the number of "failure" of group L was much higher than that of group E while the numbers of "partial success" were comparable between the two groups (Table 3).

Maternal satisfaction of group E was significantly higher than that of group L (Table 3). Other secondary outcomes including Apgar scores, presence or absence of hypotension and ephedrine or phenylephrine use, anesthetic times, fluids, transfusion, urine output, blood loss, nausea, and pain score were comparable between the two groups (Tables 3,4). Overall incidences of hypotension and severe nausea were 59\% (32/54) and $5.6 \%(3 / 54)$, respectively (Table 3 ). No incidence of severe complication or catheter-related complication was reported.

\section{Discussion}

In the present study, we showed the usefulness of electric-guided epidural confirmation with LOR technique. In addition to higher maternal satisfaction, there was a significant increase in success rates without increasing any complications.

Compared to epidural anesthesia, spinal anesthesia has several disadvantages including the risks of the extensive block, postdural puncture headache, and abrupt hypotension. Despite these shortcomings, the higher success rate of spinal anesthesia in comparison to that of epidural anesthesia (94\% vs 76\%) [4] may be the one of the important advantages. Conversely, if success rate of epidural anesthesia improves, the merit of spinal anesthesia diminishes.

After epidural anesthesia have been introduced in 1921, LOR technique and hanging drop technique were independently developed to identify the epidural space in 1932 [1]. And LOR technique is more commonly used especially in the lumbar spine compare to the hanging drop technique because there was a lack of evidence for intrinsic negative pressure in the lumbar epidural spaces [10]. However, the loss of resistance seemed to be more difficult to feel in the parturient. Lechner, et al. [11] reported lower maximum pressure just before loss of resistance and higher pressure in the epidural space in the 


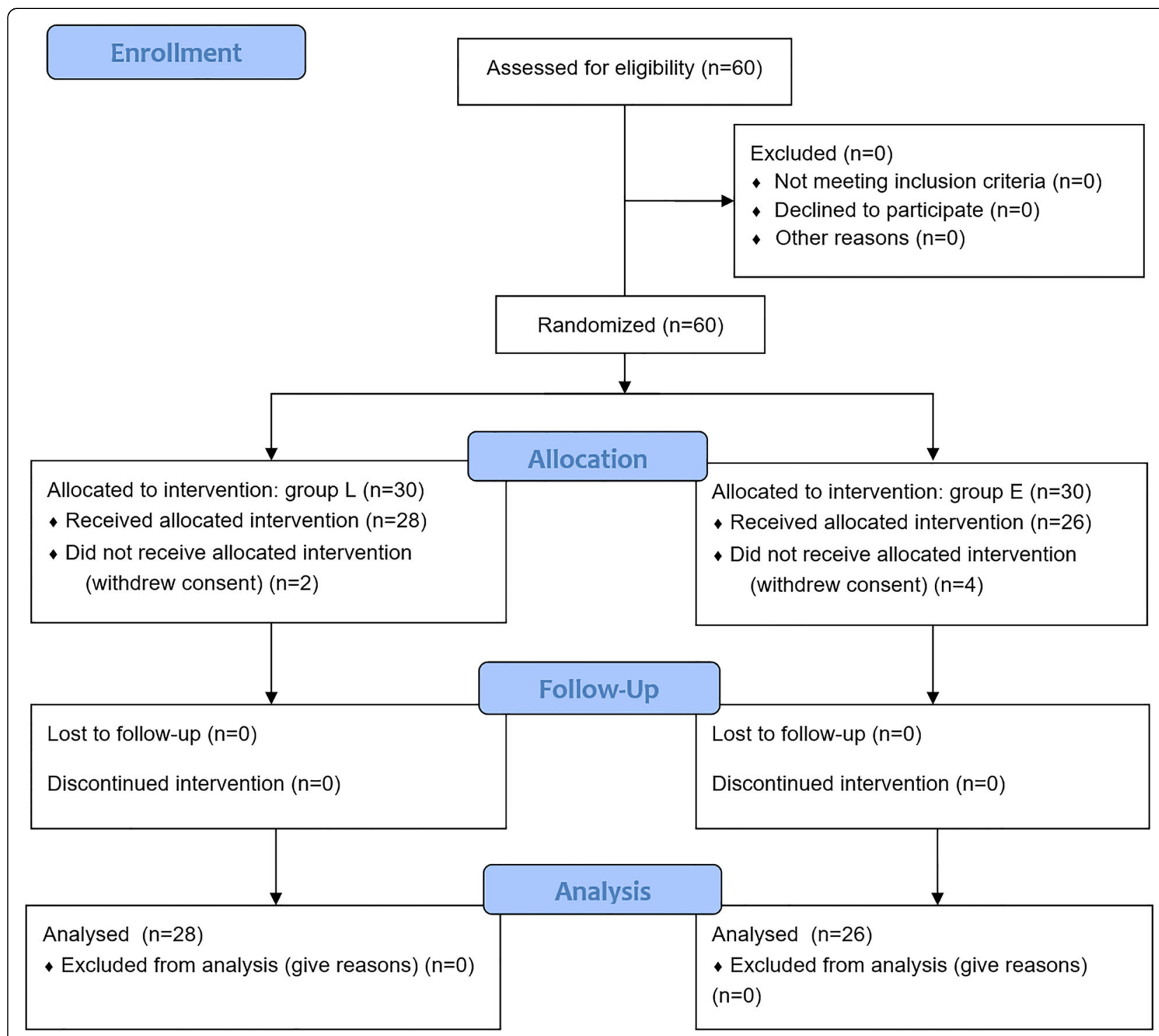

Fig. 1 CONSORT flow diagram. Group $L$ used a loss of resistance technique in the epidural cesarean section while group E used electrical epidural stimulation combined with a loss of resistance technique

parturient, compared to those in the non-parturient probably due to weakened ligament flavum and engorged epidural vein.

There were several other methods to identify the epidural space. C-arm guided epidural confirmation is not used in the obstetrics due to radiation exposure. Sonographic guided epidural confirmation can be considered as an option these days, and the use of ultrasonography is increasing with improvements in ultrasound technology [12]. However, ultrasonography requires relatively expensive equipment. Some other ways to confirm the epidural space include epidural waveform analysis [13] and electrical stimulation that we discuss in the current study.
Tsui et al. [14] first described the use of electrical stimulation to confirm catheter placement in the epidural space. Subsequently, several researchers applied epidural stimulation for catheter placement [15-17]. Previous studies showed favorable results without side effects. However, it was difficult to unify diverse guidelines. In particular, different catheter types required different reference ranges for electric current. Tsui's method, where an epidural catheter was used with a fixed electrode at the distal tip and the electric impulse was conducted through normal saline within the lumen of catheter [14], required a relatively high electric current $(1-10 \mathrm{~mA}$ at a pulse width of $0.3 \mathrm{~ms})$ to produce motor response [18]. Similar to our catheter, Charghi 
Table 2 The outcomes for the electrical stimulation

\begin{tabular}{ll}
\hline & $N=26$ \\
\hline $\begin{array}{l}\text { The minimum electric current (mA)used to } \\
\text { evoke paresthesia or muscle contraction }\end{array}$ & $1.06 \pm 0.36$ \\
$\begin{array}{l}\text { The number of cases which required } \\
\text { catheter reposition }\end{array}$ & $6(23)$ \\
Cases with unilateral response & $16(62)$ \\
Success & $13(81)$ \\
Partial success & $3(19)$ \\
Failure & $0(0)$ \\
Cases with bilateral response & $10(38)$ \\
Success & $8(80)$ \\
Partial success & $1(10)$ \\
Failure & $1(10)$ \\
\hline $\begin{array}{l}\text { Values are either the mean } \pm \text { SD or the number of patients (\%). A total of } 26 \\
\text { patients in the group E were confirmed the responses to electrical stimulation }\end{array}$
\end{tabular}

et al. [19] used a single-port, metal coil-reinforced catheter containing a removable stylet for electric conduction instead of normal saline as a priming solution. Their results were comparable to ours, but the mean stimulatory current threshold was different from Tsui's. Although the absolute value provided in Tsui's criteria was not applicable in different settings, at least it can signal catheter misplacement of intrathecal or epiradicular spaces when the values of the required current needed for electrical response were too low $[16,17]$.

The success rates of epidural anesthesia are affected by the practitioner's skill. A non-obstetric anesthesiologist's care was regarded as one of the risk factors for epidural failure when provided not only in primary epidural anesthesia for cesarean section but also in conversion of labor epidural analgesia to cesarean delivery anesthesia [6]. There were several ways to define epidural failure, such as conversion to other forms of anesthesia [20], pain during surgery [21], and failure to achieve the predefined degree of nerve block [22]. We saw that failure is due to two reasons: a) failure in finding the epidural space at all and b) mismatched level or unilateralization of drug spreading out on the epidural space. In our study, the number of "failure" in the group E was significantly reduced compared to group L. This finding suggests that the electric confirmation was effective for untrained practitioners in confirming the epidural spaces.

We considered the level of anesthesia and drugs used for epidural anesthesia. To find an insertion point, the Tuffier's line was used as a reference in our study. We regarded the transverse line connecting the tops of the iliac crests as the Tuffier's line. Kim, et al. [23] showed that the mean vertebral level of Tuffier's line in the parturient women was L3-lower vertebral level which was higher than that of non-parturient women (L4-lower vertebral level). Therefore, our target level (L2/3) of epidural injection was the level above the Tuffier's line. However, some cases that deviate from the average in the actual vertebral level were reported [23], so knowing the correct level in advance may improve the results regarding "partial success". Next, there were several concerns about the usefulness of epidural test dose in obstetrics [24]. Local anesthetics may cause unwanted prolonged motor block, but it was not a major problem in the cesarean section. However, epinephrine was not recommended due to its restricted sensitivity [25] and risk exposures regarding high myocardial oxygen consumption and low uterine blood flow [24]. For these reasons, we used lidocaine only as a test dose to exclude an intrathecal injection. We also considered lidocaine as main dose for its fast onset and ropivacaine as

Table 3 Clinical outcomes

\begin{tabular}{|c|c|c|}
\hline & $\begin{array}{l}\text { Group L } \\
(\boldsymbol{n}=28)\end{array}$ & $\begin{array}{l}\text { Group E } \\
(\boldsymbol{n}=26)\end{array}$ \\
\hline Primary outcome (complete success / partial success / failure) & $15 / 4 / 9(54 / 14 / 32)$ & $21 / 4 / 1^{*}(81 / 15 / 4)$ \\
\hline Sensitivity in finding the epidural space & 0.68 & $0.96^{*}$ \\
\hline Maternal satisfaction & $3.39 \pm 0.73$ & $4.04 \pm 0.72^{*}$ \\
\hline Ephedrine or phenylephrine use during operation / PACU & $1.23 \pm 1.46 / 0.32 \pm 0.67$ & $0.89 \pm 1.07 / 0.23 \pm 0.59$ \\
\hline Hypotension (Y / N) & 17 / $11(61 / 39)$ & $15 / 11(58 / 42)$ \\
\hline Nausea $(Y / N)$ & $2 / 26(7 / 93)$ & $1 / 25(4 / 96)$ \\
\hline Pain score (VAS) at discharge in the PACU & $1.25 \pm 1.40$ & $1.65 \pm 1.41$ \\
\hline $1 \mathrm{~min}$ Apgar & $8.18 \pm 1.16$ & $7.69 \pm 1.72$ \\
\hline 5 min Apgar & $9.54 \pm 0.58$ & $9.23 \pm 0.82$ \\
\hline
\end{tabular}

Values are either the mean \pm SD or the number of patients (\%). Group $L$ used a loss of resistance technique in the epidural cesarean section while group $E$ used electrical epidural stimulation combined with a loss of resistance technique. Sensitivity in finding the epidural space was calculated as "complete success + partial success / complete success + partial success + failure" in each group. The calculation of the specificity was not available due to the methodological limitation. Maternal satisfaction was rated on a scale ranging from 1 (very unsatisfied) to 5 (very satisfied). Group E showed higher success rate, sensitivity in finding the epidural space and maternal satisfaction compared to group L. The other outcomes were comparable between the two groups. ${ }^{*} p<0.05$ compared to group L. Abbreviations: VAS Visual analogue scale, PACU Post-anesthesia care unit 
Table 4 Required time and intake/output in the perioperative periods

\begin{tabular}{lll}
\hline & $\begin{array}{l}\text { Group L } \\
(\boldsymbol{n}=28)\end{array}$ & $\begin{array}{c}\text { Group E } \\
(\boldsymbol{n}=26)\end{array}$ \\
\hline Time interval between the admission to the operating room and the start of the operation (min.) & $32.37 \pm 12.46$ & $27.81 \pm 15.92$ \\
Time A (interval between drape and test dose administration) (min.) & $8.79 \pm 3.97$ & $8.81 \pm 3.20$ \\
Time B (time it took to confirm epidural space, administer main dose and to place epidural catheter) (min.) & $4.61 \pm 2.50$ & $4.67 \pm 2.16$ \\
Operation time (min.) & $48.93 \pm 11.61$ & $50.77 \pm 16.82$ \\
Time interval between the end of the operation and the discharge to PACU (min.) & $6.70 \pm 4.11$ \\
Crystalloid (ml) & $1060.37 \pm 469.41$ & $1128.08 \pm 388.15$ \\
Colloid (ml) & $37.04 \pm 133.44$ & $53.85 \pm 152.92$ \\
Transfusion (pint) & $0.12 \pm 0.43$ & $0.08 \pm 0.39$ \\
Urine output (ml) & $249.82 \pm 144.49$ & $224.23 \pm 115.27$ \\
Blood loss (ml) & $479.63 \pm 138.74$ & $519.92 \pm 209.76$ \\
\hline
\end{tabular}

Values are the mean \pm SD. Group L used a loss of resistance technique in the epidural cesarean section, whereas group E used electrical epidural stimulation combined with a loss of resistance technique. Perioperative time period in each step and intake / output during perioperative periods were comparable between the two groups. Abbreviation: PACU Post-anesthesia care unit

supplementary dose for anesthetic quality [26]. Because of the simplicity of our regimen (no mixed solution), the risk of drug misadministration by novices appeared to be minimal, and once the epidural has been found, electrical stimulation did not seem to have a significant effect on the partial success rate.

The other outcomes in the study showed the efficiency and the safety of electrical stimulation. In almost all cases, electrical stimulation was performed during the wait time after the test dose administration. Although 6 patients in the group E required catheter repositioning due to lack of response to the electrical stimulation, the delay time was up to $5 \mathrm{~min}$ from the average. The difference in Time B, which includes the time for catheter placement, was only $0.06 \mathrm{~min}$ between the two groups (Table 4). Therefore, the risk of time consumption was minimized. During the study, no catheter-related adverse event including intrathecal or intravascular injection was reported, and the electrical stimulation did not affect the Apgar score. The most common complication was hypotension, which appeared to be a side effect from the neuraxial block. In addition, the incidence of hypotension and the use of cardiovascular drugs during perioperative period were comparable between the two groups. Most of the hypotensive events were gradually developed, and all were successfully resolved without any sequelae.

Before conducting this study, we tried to stimulate the exact level by identifying the corresponding radiating paresthesia, but the electrical stimulation seemed to have a low spatial resolution. In addition, when the catheter was located to one side, the nerve roots were easily stimulated, and the current value was lowered. There were also individual variations and a wide range of required currents due to possibility of epidural adhesion, epidural vein engorgement or any other anatomical variations.
For these reasons, electrical stimulation has a limitation in confirming an appropriate level of anesthesia. Fortunately, most of the unilateral stimulations resulted in bilateral anesthesia. Large doses of local anesthetics seemed to extend to the contralateral side. Therefore, as a straightforward guideline, once a reliable response to the stimulation is detected even in unilateral side, we recommend proceeding to the next step.

There were other limitations as well. First, the usefulness of electrical stimulation may not be evident for the well-trained anesthesiologist. In statistical perspective, the higher success rate in the LOR-only group requires the greater number of sample size to have a significant meaning. Second, the guidewire inside the epidural catheter may increase a risk of incidental intrathecal or vascular puncture in theory. However, this issue has not been reported in this study as well as in Charghis's study [19] which was similar to ours. Third, there was a methodological limitation in allocation concealment (double blind). During the electrical stimulation, the patient and the practitioner may notice the group assignment. However, another blinded independent anesthesiologist assessed the outcomes in the postoperative period to minimize the performance bias. Finally, the use of a test dose could require more electrical current to overcome sensorimotor blockade of lidocaine although the test dose did not appear to have a significant effect in this study.

Despite these limitations, our study suggests several advantages and implications. First was the type of catheter. There was a risk of air lock which disturbs the current flow down the column of saline contained inside the Tsui's catheter [14]. In our study, we used the epidural catheter with a built-in conductive guidewire. Our devices seemed to be simple while reducing the risk described above. The minimum currents of our device 
were also lower than other electrical epidural stimulation methods. This may reduce the risk of injury from electrical stimulation. Second, the method and the results in the present study may contribute as a guideline and reference values when using our catheter. However, it should be noted that the reference value can be changed in other situations including non-obstetric patients or patients known to have history of lumbar disease or surgery. Third, high maternal satisfaction suggested that electrical stimulation did not appear to be an unpleasant or uncomfortable experience to the patient. In fact, no complaints or problems with electrical stimulation occurred during the study. To our knowledge, this study was the first application of epidural electrical stimulation for cesarean section. Although the method we improved had not changed dramatically, the impact has been substantial. Taken together, at least in the obstetric area, our findings supported the usefulness of electrical stimulation.

We think that our method would be more improved when used in conjunction with ultrasonography because ultrasound guided technique may provide a desired level of anesthesia. In detail, we recommend planning the epidural technique in advance while using ultrasonography to determine the level of vertebral body and the depth and location of epidural space, and then confirming with electrical stimulation. Further studies are required to determine whether the combined use of electrical stimulation and ultrasonography is useful for difficult epidural procedures.

\section{Conclusion}

Confirmation of the epidural space using electrical stimulation improved success rate as well as maternal satisfaction without wasting time, fetal distress or any other risks in the cesarean section. It seemed to be effective for inexperienced clinicians and those with recent gap in experience.

\section{Abbreviations}

LOR: Loss of resistance; PACU: Post-anesthesia care unit; VAS: Visual analogue scale

\section{Acknowledgements}

Not applicable.

\section{Authors' contributions}

YSK, CHL and SSC were major contributors in conducting the study and writing the manuscript. HSK and HJ helped to conduct study, recruited patients, performed data acquisition. MKL helped to design the study, analyzed the data and revised the manuscript. All authors gave approval of manuscript that to be submitted.

\section{Funding}

There are no funding sources for this article.

\section{Availability of data and materials}

The datasets of the current study are available from the corresponding author on reasonable request.
Ethics approval and consent to participate

Korea University Guro Hospital Institutional Review Board approved of the study protocol. All subjects signed informed consent documents prior to enrollment.

\section{Consent for publication}

Not applicable.

\section{Competing interests}

The corresponding author, Sang Sik Choi, is the one of developers for RegionalStim ${ }^{\circledast}$ epidural catheter. The other authors declare no competing interests.

Received: 19 February 2020 Accepted: 1 June 2020

Published online: 10 June 2020

\section{References}

1. Chau A, Tsen LC. Update on modalities and techniques for labor epidural analgesia and anesthesia. Adv Anesth. 2018;36(1):139-62.

2. Sharma RM, Setlur R, Bhargava AK, Vardhan S. Walking epidural : an effective method of labour pain relief. Med J Armed Forces India. 2007;63(1):44-6.

3. Maxwell BG, El-Sayed YY, Riley ET, Carvalho B. Peripartum outcomes and anaesthetic management of parturients with moderate to complex congenital heart disease or pulmonary hypertension. Anaesthesia. 2013; 68(1):52-9.

4. Kinsella SM. A prospective audit of regional anaesthesia failure in 5080 caesarean sections. Anaesthesia. 2008;63(8):822-32.

5. Orbach-Zinger S, Friedman L, Avramovich A, llgiaeva N, Orvieto R, Sulkes J, Eidelman LA. Risk factors for failure to extend labor epidural analgesia to epidural anesthesia for cesarean section. Acta Anaesthesiol Scand. 2006; 50(8):1014-8.

6. Bauer ME, Kountanis JA, Tsen LC, Greenfield ML, Mhyre JM. Risk factors for failed conversion of labor epidural analgesia to cesarean delivery anesthesia: a systematic review and meta-analysis of observational trials. Int J Obstet Anesth. 2012;21(4):294-309.

7. Hermanides J, Hollmann MW, Stevens MF, Lirk P. Failed epidural: causes and management. Br J Anaesth. 2012:109(2):144-54.

8. Kopacz DJ, Neal JM, Pollock JE. The regional anesthesia "learning curve" what is the minimum number of epidural and spinal blocks to reach consistency? Reg Anesth. 1996;21(3):182-90.

9. Lee CH, Choi SS, Lee MK, Kim JE, Chung DI, Lee M. Electric stimulationguided epidural analgesia for vaginal delivery: a randomized prospective study. PLoS One. 2019;14(1):e0209967.

10. Todorov L, VadeBoncouer T. Etiology and use of the "hanging drop" technique: a review. Pain Res Treat. 2014;2014:146750.

11. Lechner TJM, van Wijk MGF, Jongenelis AAJ, Rybak M, van Niekerk J, Langenberg CJM. The use of a sound-enabled device to measure pressure during insertion of an epidural catheter in women in labour. Anaesthesia. 2011;66(7):568-73

12. Lee A, Loughrey JPR. The role of ultrasonography in obstetric anesthesia. Best Pract Res Clin Anaesthesiol. 2017;31(1):81-90.

13. Al-Aamri I, Derzi SH, Moore A, Elgueta MF, Moustafa M, Schricker T, Tran DQ. Reliability of pressure waveform analysis to determine correct epidural needle placement in labouring women. Anaesthesia. 2017;72(7):840-4.

14. Tsui $B C H$, Gupta S, Finucane B. Confirmation of epidural catheter placement using nerve stimulation. Can J Anaesth. 1998;45(7):640-4.

15. Goobie SM, Montgomery CJ, Basu R, McFadzean J, O'Connor GJ, Poskitt K, Tsui BCH. Confirmation of direct epidural catheter placement using nerve stimulation in pediatric anesthesia. Anesth Analg. 2003;97(4):984-8.

16. Jeong JS, Shim JC, Shim JH, Kim DW, Kang MS. Minimum current requirement for confirming the localization of an epiradicular catheter placement. Korean J Anesthesiol. 2012;63(3):238-44.

17. Sutherland MA, Viscomi CM, Dominick TS, Anderson EL. Minimum current requirements for epidural stimulation test confirmation of epidural and intrathecal catheter placement. Reg Anesth Pain Med. 2009;34(6):575-7.

18. Tsui BC, Gupta S, Finucane B. Determination of epidural catheter placement using nerve stimulation in obstetric patients. Reg Anesth Pain Med. 1999; 24(1):17-23.

19. Charghi R, Chan SY, Kardash KJ, Finlayson RJ, Tran DQH. Electrical stimulation of the epidural space using a catheter with a removable stylet. Region Anesth Pain M. 2007;32(2):152-6. 
20. Shibli KU, Russell IF. A survey of anaesthetic techniques used for caesarean section in the UK in 1997. Int J Obstet Anesth. 2000;9(3):160-7.

21. Riley ET, Papasin J. Epidural catheter function during labor predicts anesthetic efficacy for subsequent cesarean delivery. Int J Obstet Anesth 2002;11(2):81-4.

22. Goring-Morris J, Russell IF. A randomised comparison of $0.5 \%$ bupivacaine with a lidocaine/epinephrine/fentanyl mixture for epidural top-up for emergency caesarean section after "low dose" epidural for labour. Int J Obstet Anesth. 2006;15(2):109-14

23. Kim SH, Kim DY, Han Jl, Baik HJ, Park HS, Lee GY, Kim JH. Vertebral level of Tuffier's line measured by ultrasonography in parturients in the lateral decubitus position. Korean J Anesthesiol. 2014;67(3):181-5.

24. Massoth C, Wenk M. Epidural test dose in obstetric patients: should we stil use it? Curr Opin Anaesthesiol. 2019;32(3):263-7.

25. Norris MC, Fogel ST, Dalman H, Borrenpohl S, Hoppe W, Riley A. Labor epidural analgesia without an intravascular "test dose". Anesthesiology. 1998:88(6):1495-501.

26. Hillyard SG, Bate TE, Corcoran TB, Paech MJ, O'Sullivan G. Extending epidural analgesia for emergency caesarean section: a meta-analysis. Br J Anaesth. 2011;107(5):668-78.

\section{Publisher's Note}

Springer Nature remains neutral with regard to jurisdictional claims in published maps and institutional affiliations.

Ready to submit your research? Choose BMC and benefit from:

- fast, convenient online submission

- thorough peer review by experienced researchers in your field

- rapid publication on acceptance

- support for research data, including large and complex data types

- gold Open Access which fosters wider collaboration and increased citations

- maximum visibility for your research: over $100 \mathrm{M}$ website views per year

At BMC, research is always in progress.

Learn more biomedcentral.com/submissions 